\title{
The Effect of 10kv Lines Reactive Compensation Switching Mode for the Loss Impact
}

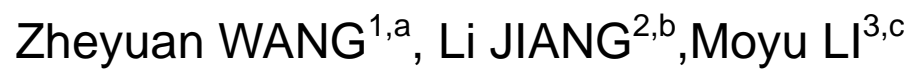 \\ ${ }^{1}$ State Grid Liaoning Electric Power Supply Jinzhou Electric Power Supply Company, China \\ ${ }^{2}$ China National Petroleum Corporation Jinzhou Liaoning Sales Branch, China \\ ${ }^{3}$ State Grid Liaoning Electric Power Company Limited Maintenance Branch Company,China

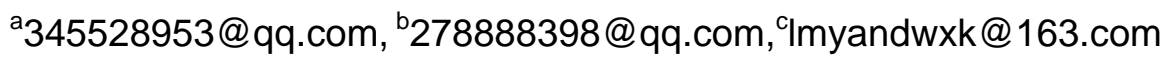

Keywords: Rural power distribution network, 10 kV line, Reactive compensation, switching mode, Compare loss impact

Abstract: $10 \mathrm{kV}$ lines reactive compensation of the rural power distribution network can effectively decrease the loss, improve power factor, improve the voltage quality. $10 \mathrm{kV}$ lines automatic switching control of reactive power compensation devices, are usually classified as according to the voltage switching and according to the power factor switching. At the same time, they have to adapt to the line points method. This paper compares the reactive power flows and the loss impact of two switching modes by practical calculation. Finally, switching according to the voltage for loss is superior.

\section{Introduction}

With the increase of power distribution system load, reactive power demand also increases accordingly. At present, the reactive power compensation ways of our country rural distribution network mainly are the following four ones, (1) the substation centralized compensation;(2) the compensation along with the transformer;(3)the random compensation;(4)the reactive power compensation of $10 \mathrm{kV}$ lines. The first mode did not the distribution of reactive power flow under the transformer substation; The second and third are effective measures of local reactive power balancing, are mature technology; The fourth mode is a supplement to the second and third. Especially for the lines of rural power distribution network, which are very long, dispersive loads, low power factor, reactive compensation is very important. How to make reactive compensation of $10 \mathrm{kV}$ distribution network more scientific and more reasonable, it will require additional research.

\section{The loss of one $10 \mathrm{kV}$ distribution line before compensation}

One $10 \mathrm{kV}$ distribution line, the total length of main line is $6.31 \mathrm{~km}$, and all lines adopt the LGJ $95 / 20$ type. The wire paramenter is $R=0.3019 \Omega / \mathrm{km}$. Before compensation, active power which is the head of line, is $640 \mathrm{~kW}$, reactive power is $430 \mathrm{kVAR}$, the power factor is 0.83 . The simplified line is as shown in figure 1.

\subsection{The active power loss before compensation}

$$
\begin{aligned}
& \Delta P_{83-85}=\frac{P_{85}^{2}+Q_{85}^{2}}{U_{P j}^{2}} \cdot R_{85-83} \times 10^{-3}=0.004947 \mathrm{~kW} \\
& \Delta P_{83-71}=\frac{\left(P_{83}+P_{85}\right)^{2}+\left(Q_{83}+Q_{85}\right)^{2}}{U_{P j}^{2}} \cdot R_{83-71} \times 10^{-3}=0.04018 \mathrm{KW}
\end{aligned}
$$

And so on: $\Delta P_{3-1}=\frac{\left(P_{3}+P_{3-85}\right)^{2}+\left(Q_{3}+Q_{3-85}\right)^{2}}{U_{P j}^{2}} \cdot R_{1-3} \times 10^{-3}=0.04044 K W h$

The total active loss: $\Delta P=\Sigma \Delta P_{i}=1.7489 k W$ 
The rate of active power loss: $\Delta P \%=\frac{\Delta P}{P_{1}}=\frac{1.7489}{640}=0.2734 \%$

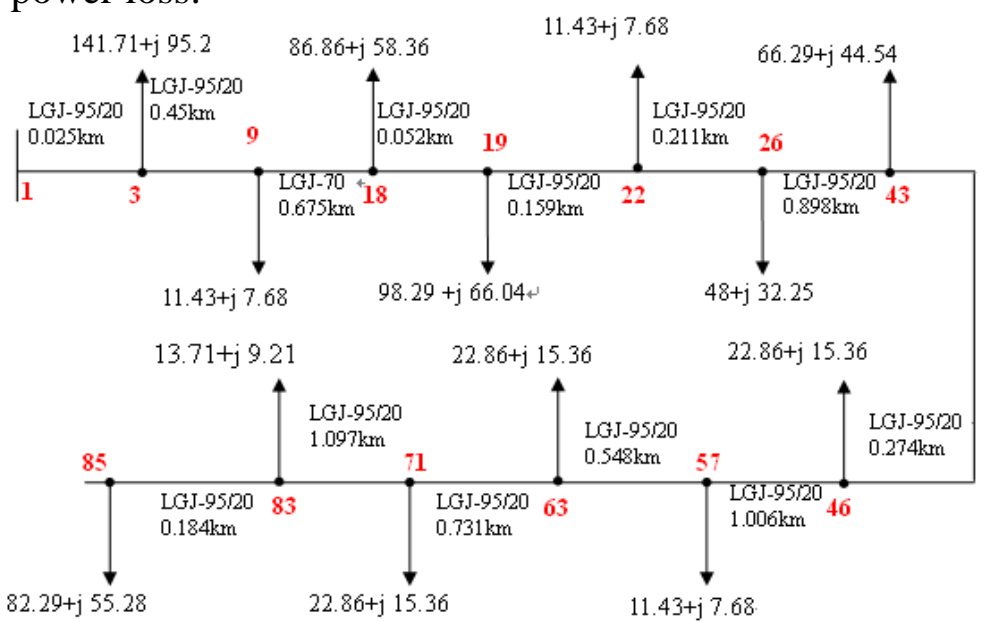

Figure 1 The simplified figure of one $10 \mathrm{kV}$ distribution line before compensation

\section{2 before the compensation voltage loss}

$$
\begin{aligned}
& \Delta U_{1-3}=\frac{P_{1} R_{1-3}+Q_{1} X_{1-3}}{10.5} \times 10^{-3}=0.0008667(\mathrm{kV}) \\
& \Delta U_{3-9}=\frac{\left(P_{1}-P_{3}\right) R_{3-9}+\left(Q_{1}-Q_{3}\right) X_{3-9}}{\left(U_{1}-\Delta U_{1-3}\right)}=0.01219(\mathrm{kV})
\end{aligned}
$$

And so on: $\Delta U_{83-85}=\frac{P_{85} R_{83-85}+Q_{85} X_{83-85}}{\left(U_{71}-\Delta U_{71-83}\right)} \times 10^{-3}=0.0008228(\mathrm{kV})$

The total drop of voltage: $\Delta U=\Sigma \Delta U_{i}=U_{1}-\left(U_{83}-\Delta U_{83-85}\right)=0.07633(k V)$

The rate of voltage loss: $\Delta U \%=\frac{\Delta U}{U_{1}}=\frac{0.07633}{10.5}=0.727 \%$

\section{The loss impact under the different switching modes}

Because the reactive load is constantly changing, that need some compensating capacitors, which can automatic switching, in order to realize the best of compensation. This is no unified criterion to judge automatic switching of compensating capacitors. Because the conditions of reactive compensation and the controlling targets are different, the reactive compensations of rural power distribution network are usually classified as according to the voltage switching and according to the power factor switching. At the same time, they have to adapt to the line points method.

In order to convenient comparison and analysis, the $10 \mathrm{kV}$ line of figure 1 set three compensation points, each point of the compensation capacity is $Q_{C i}=120 \mathrm{kVAR}$.

\subsection{According to the power factor switching}

The principle of the control according to the power factor is that, by sampling power factor, according to the power factor automatic parallel capacitor group. If the power factor is lower than the lowest limit , input capacitor; If the power factor is higher than the highest limit , cut capacitor; According to the power factor points method, reactive power flow accumulate upward from the line end, accumulate to the compensation capacity, that point is the first compensation point; Then accumulate upward to the compensation capacity of the second point, that point is the second compensation point, and so on. As figure 1 , one $10 \mathrm{kV}$ line station points according to the power factor, the compensation points are 3 nodes, 19 nodes, 43 nodes respectively.

According to the power factor for reactive power compensation and reactive current distribution is shown as figure 2 .

According to the algorithm described above, the results of according to the power factor switching calculation are as follows:

The total active loss: $\Delta P=\Sigma \Delta P_{i}=1.6249 \mathrm{~kW}$ 
The rate of active power loss: $\Delta P \%=\frac{\Delta P}{P_{1}}=\frac{1.2302}{640}=0.2539 \%$

The total drop of voltage: $\Delta U=\Sigma \Delta U_{i}=U_{1}-\left(U_{83}-\Delta U_{83-85}\right)=0.06158(k V)$

The rate of voltage loss: $\Delta U \%=\frac{\Delta U}{U_{1}}=\frac{0.06158}{10.5}=0.5876 \%$

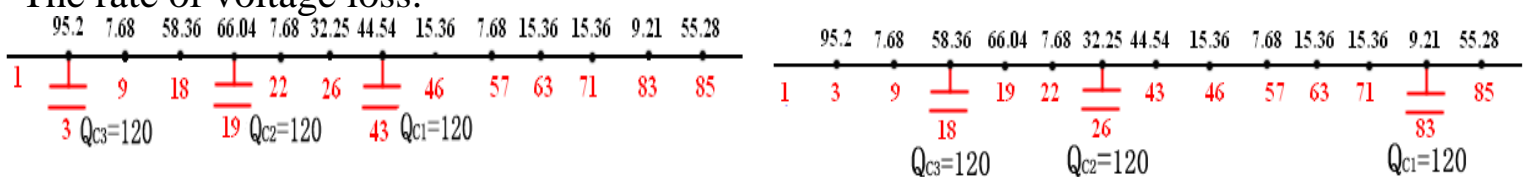

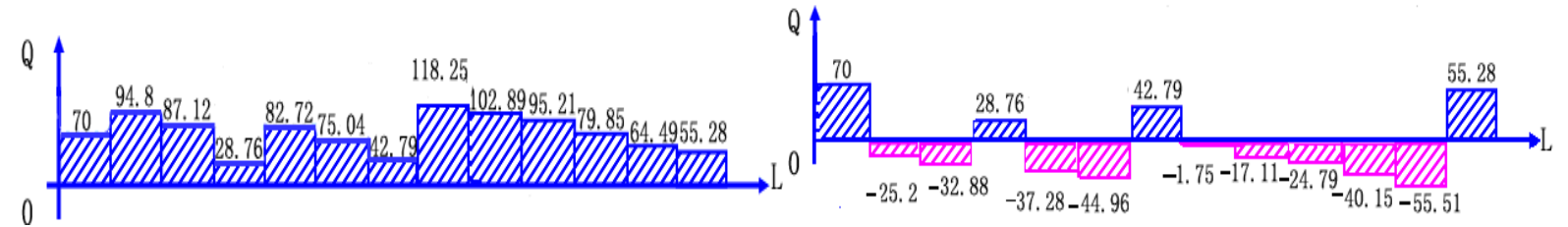

Figure 2 According to the power factor for reactive power compensation and reactive current

Figure 3 According to the voltage for reactive power compensation and reactive current

\subsection{According to the voltage switching}

The principle of the control according to the voltage is that, by sampling the voltage, according to the voltage automatic parallel capacitor group. If the voltage is lower than the lowest limit , input capacitor; If the voltage is higher than the highest limit, cut capacitor; According to the voltage points method, reactive power flow accumulate upward from the line end, accumulate to the half of the compensation capacity, its compensation range is accumulating to the other half, that point is the first compensation point; Then accumulate upward to the half of compensation capacity of the second point, that point is the second compensation point, its compensation range is accumulating to the other half , and so on. As figure 1 , one $10 \mathrm{kV}$ line station points according to the voltage, the compensation points are 18 nodes, 26 nodes, 83 nodes respectively.

According to the voltage for reactive power compensation and reactive current distribution is shown in figure 3.

According to the algorithm described above, the results of according to the voltage switching calculation are as follows:

The total active loss: $\Delta P=\Sigma \Delta P_{i}=1.2302 \mathrm{~kW}$

The rate of active power loss:

$$
\Delta P \%=\frac{\Delta P}{P_{1}}=\frac{1.2302}{640}=0.1922 \%
$$

The total drop of voltage: $\Delta U=\Sigma \Delta U_{i}=U_{1}-\left(U_{83}-\Delta U_{83-85}\right)=0.03687(k V)$

The rate of voltage loss:

$$
\Delta U \%=\frac{\Delta U}{U_{1}}=\frac{0.07633}{10.5}=0.3511 \%
$$

\section{3 loss reduction effect comparison}

(1) The comparison of the reactive power flow 

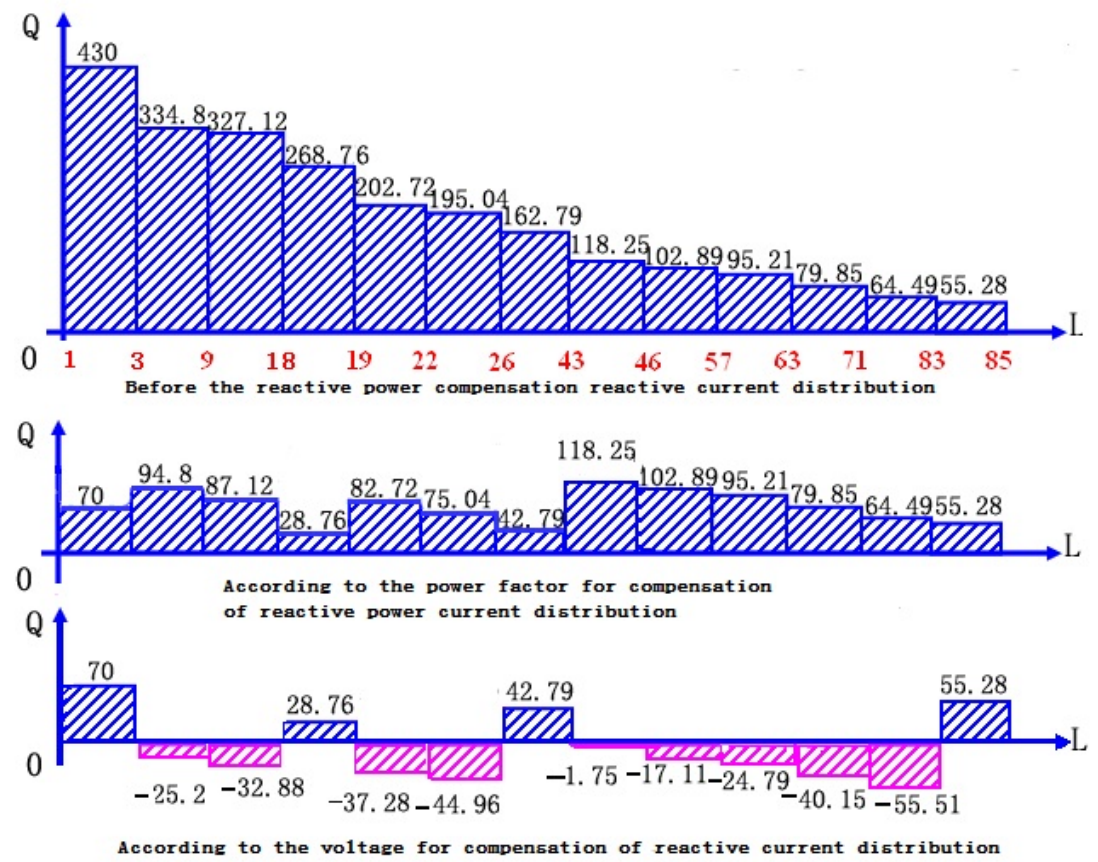

Figure 4 The comparison of reactive power flows in different modes (2)The comparison of the voltage loss

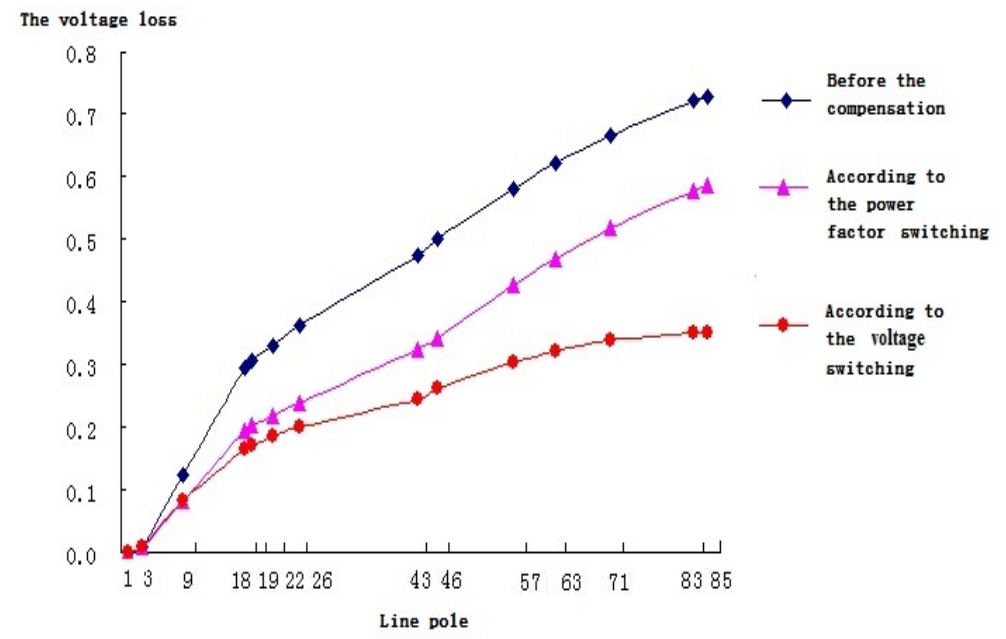

Figure 5 The comparison of the voltage loss

(3) The comparison of the active loss and the voltage loss

Table 1. The comparison of the active loss and the voltage loss

\begin{tabular}{|c|c|c|c|}
\hline Line status & The active loss & The voltage loss & The power factor \\
\hline Before the compensation & $0.2733 \%$ & $0.727 \%$ & 0.83 \\
\hline $\begin{array}{c}\text { According to the power } \\
\text { factor switching }\end{array}$ & $0.2539 \%$ & $0.5876 \%$ & 0.99 \\
\hline $\begin{array}{c}\text { According to the voltage } \\
\text { switching }\end{array}$ & $0.1922 \%$ & $0.3511 \%$ & 0.99 \\
\hline
\end{tabular}

\section{Conclusion}

$10 \mathrm{kV}$ lines reactive compensation of the rural power distribution network can effectively decrease the loss, improve power factor, improve the voltage quality. $10 \mathrm{kV}$ lines automatic switching control of reactive power compensation devices, are usually classified as according to the voltage switching and according to the power factor switching. Through the calculation and comparison of the instance, the effect of the voltage switching is more significant, the voltage 
switching can effectively improve the voltage quality and reduce the loss of active power.

It is worth mentioning, $10 \mathrm{kV}$ lines of the rural power distribution network identify the position and the capacity of the compensation point. Control automatic switching of the capacitor is order to prevent over compensation in low load stage, that could through the remote communication technology and network technology realize that the bidirectional data exchange between the upper and lower computer. The measured voltage and switching condition, which is gathered by the lower computer, transfer to the upper computer in the dispatching room through GPRS, then the upper computer centralize the power factor and reactive power of the substation export. Determine the switching conditions of every compensation point, then transfer switching order to the lower computer, thus achieve the power factor and voltage double control purposes. This has realized in some cities, it can make the average power factor of the substation export above 0.95.It has received remarkable economic benefit and social benefit.

\section{Reference}

[1] Zhang Yongjun Ren Zhen, liao America and Britain, etc. $10 \mathrm{kV}$ line long stem reactive power optimization compensation [J]. Journal of China power, 2000, (9).

[2] ZhuangKanQin, li xingyuan. Substation voltage and reactive power control strategy is implemented [J]. Automation of electric power systems, 2001, (8).

[3] Hu Haiyan, liu, Wu Xiao meng. Automatic reactive power compensation device is installed on the low voltage side of distribution network optimization planning [J], relay, 2004, (19).Chen Wenbin

[4]. Power system reactive power optimization and voltage adjustment [M]. Shenyang: liaoning science and technology press, 2003.

[5] LeiMing. Network loss reduction and energy saving manual [M]. Beijing: China power press, 2005.

[6] PiaoZaiLin Tan Dongming, human. $10 \mathrm{kV}$ distribution line reactive power optimization research and implementation of the intelligent system [J]. Journal of agricultural engineering, 2009, (12). 